\title{
Effect of prepregnancy anti-inflammatory diet on pregnant women with endometriosis: The Japan Environment and Children's Study
}

\author{
Hyo Kyozuka ${ }^{1}$, Hidekazu Nishigori ${ }^{1}$, Tsuyoshi Murata ${ }^{1}$, Toma Fukuda ${ }^{1}$, Akiko Yamaguchi ${ }^{1}$, \\ Aya Kanno ${ }^{1}$, Shun Yasuda ${ }^{1}$, Akiko Sato ${ }^{1}$, Yuka Ogata ${ }^{1}$, Masahito Kuse ${ }^{1}$, Mitsuaki \\ Hosoya $^{1}$, Seiji Yasumura ${ }^{1}$, Koichi Hashimoto ${ }^{1}$, and Keiya Fujimori ${ }^{1}$ \\ ${ }^{1}$ Fukushima Medical University
}

May 19, 2020

\begin{abstract}
Objective: To investigate the correlation of prepregnancy dietary inflammatory index (DII) with obstetric outcomes in women with endometriosis. Design: Prospective cohort study Setting: Japan Population: We identified 88,398 Japanese women ( $\mathrm{n}=85,149$ without endometriosis and $\mathrm{n}=3,249$ with endometriosis) who were recruited in the Japan Environment and Children's study (JECS) between January 2011 and March 2014. Methods: Participants were categorised according to DII quintiles (Q1 and Q5 were the most pro-inflammatory and most anti-inflammatory groups, respectively) and stratified according to the presence or absence of endometriosis. Women with endometriosis were further categorised based on conceptions after assisted reproductive technology. Main outcomes were preterm birth (PTB) and low birth weight (LBW) infant. A multiple logistic regression model was used to estimate the effect of anti-inflammatory diet on PTB before 37 or 34 weeks and LBW $<2500 \mathrm{~g}$ or 1500 g. Results: In women with endometriosis without ART, Q5 significantly decreased the risk of PTB before $<34$ weeks (aOR 0.25, 95\% CI 0.07-0.83) and LBW < $1500 \mathrm{~g}$ (aOR 0.07, 95\% CI 0.01-0.60). Conclusions: This study suggested a distinctive effect of anti-inflammatory diet on more severe obstetrics outcomes, specifically PTB before 34 weeks and LBW $<1500$ g, among women with endometriosis. Moreover, preconception lifestyle may improve perinatal mortality and morbidity among women with endometriosis. Funding: None
\end{abstract}

\section{INTRODUCTION}

Endometriosis occurs in $10 \%$ of women of reproductive age, is characterised by ectopic proliferation of the endometrial tissue of the uterus, and is commonly associated with chronic pelvic pain and infertility. ${ }^{1}$ It occurs in up to $50 \%$ of women with infertility. ${ }^{2}$ A recent study has shown that inflammation leads to the elevation of components of signalling pathways such as mitogen-activated protein kinase in endometriosis ${ }^{3,4}$; therefore, treatment for chronic inflammation could be a potential target of therapy for endometriosis. Although several clinical managements for infertility, including surgical debulking of endometriosis lesion and assisted reproductive treatment, have been proposed, ${ }^{5}$ a recent systematic review and meta-analysis suggests that women with endometriosis are also at risk of obstetric complications such as preterm birth (PTB) and low birth weight (LBW) ${ }^{6}$ resulting in long-term sequelae such as neurodevelopment disorders of offspring. Neurodevelopment morbidity is thought to be affected by intrauterine inflammation and earlier gestational age..$^{7-9}$

Diet is thought to actively influence the regulation of chronic inflammation. A high-calorie, high-fat diet (such as diets including Western food), promotes inflammation, and consumption of Western food exposes the body to recurrent inflammation. ${ }^{10}$ Consequently, several diseases such as cardiovascular disease, diabetes mellitus, thrombosis, asthma, and depression may occur. ${ }^{11-13}$ By contrast, many vegetables and foods rich in minerals, such as traditional Japanese food and Mediterranean food, have anti-inflammatory effects. ${ }^{14,15}$ 
Recently, the concept of pro-inflammatory and anti-inflammatory diets has been reported. The dietary inflammatory index (DII) is used to assess the inflammatory potential of an individual's diet. ${ }^{16}$ The DII has been proved to be associated with non-communicable diseases such as cancer, cardiovascular disease, obesity, type 2 diabetes mellitus, and asthma. ${ }^{17}$

In our previous study using the largest Japanese birth cohort study, we reported that a high DII score (proinflammatory effect) before pregnancy leads to leukocytosis during the first trimester and a low DII score (anti-inflammatory diet) decreases the risk of PTB and LBW. ${ }^{18}$ Therefore, changing one's dietary habit for an anti-inflammatory diet before pregnancy could potentially prevent these obstetric complications. To our best knowledge, no study has examined the correlation between prepregnancy dietary pattern and obstetric outcome among women with endometriosis.

We hypothesised that a prepregnancy anti-inflammatory diet might reduce the PTB risk, especially among women with endometriosis. Hence, this study aimed to investigate the effect of prepregnancy antiinflammatory diet, by means of DII score, on obstetric outcomes among women with endometriosis using the largest Japanese birth cohort study.

\section{METHODS}

\section{Study design}

In this study, data from the Japan Environmental Children's Study (JECS), a government-funded birth cohort study that started in January 2011, were used. This survey investigated the effect of several environmental factors on children's health. ${ }^{19}$ Eligibility requirements of JECS participants (mothers) were as follows: (1) living in the study area at the time of application and were expected to live in Japan in the near future; (2) expected delivery date was between August 1, 2011, and mid-2014; and (3) could participate without difficulty (i.e. they could answer the self-management questionnaire). Written informed consent was obtained from all participating women.

The JECS protocol was reviewed and approved by the Ministry of the Environment's Institutional Review Board on Epidemiological Studies and by the Ethics Committees of all participating institutions. The JECS was conducted in accordance with the Helsinki Declaration and other nationally valid regulations and guidelines.

\section{Data collection}

We used the dataset released in June 2016 (dataset: jecs-ag-20160424) for this study. This dataset consisted of three types of information: (1) self-reported questionnaire obtained around the first trimester, including medical background (e.g. endometriosis, uterine myoma, adenomyosis, method of conception, maternal height, and maternal weight before pregnancy), or food frequency questionnaires (FFQs); (2) self-reported questionnaire collected during the second/third trimester, including socioeconomic status such as maternal education or household income; and (3) obstetrics outcome that was retrieved from the medical records of each subject's institution. In the present analysis, we used the FFQ data that were completed during the first trimester, and diet intake was assessed 1 year before pregnancy. This tool was used in the JECS and has been used as a self-administered diet questionnaire in previous Japanese epidemiological studies. ${ }^{20}$ In the present study, we excluded cases with insufficient data and multiple pregnancies.

\section{Calculation of DII}

The DII score is a comprehensive indicator of daily inflammatory and anti-inflammatory meal contents developed by Shivappa et al. ${ }^{16}$ The greater the DII score, the more the pro-inflammatory effect of the diet. A higher negative value indicates a more anti-inflammatory diet. The method of calculation of DII in JECS data was previously reported. ${ }^{18}$ In brief, 30 food parameters were obtained from each participant's FFQ, including energy, carbohydrate, protein, total fat, alcohol, fibre, cholesterol, saturated fat, monounsaturated fatty acids (MUFAs), polyunsaturated fatty acids (PUFAs), fatty acids ( $\mathrm{n}-3$ and $\mathrm{n}-6$ FAs), niacin, thiamin, riboflavin, iron, magnesium, zinc, selenium, folic acid, $\beta$-carotene, vitamins A, B-12, B-6, C, D, and E, 
garlic, ginger, and onion. The DII score of each participant was calculated as follows: First, dietary data were linked to a worldwide database that provided a robust estimate of the mean and standard deviation (SD) for each parameter included in the DII. ${ }^{16}$ The Z score was calculated by subtracting the standard global mean from the reported amount and dividing the result by the SD. The Z scores were not normally distributed (right skewing); thus, the $\mathrm{Z}$ score of each value was converted to a centered percentile score. Then, the centered percentile score for each food parameter was multiplied by the respective food parameter effect score (obtained by reviewing a total of 1943 research articles to determine the relationship between food parameters and inflammation, as well as by scoring) to obtain a food parameter-specific DII score, which were all summed to create the overall DII score for each participant. DII $=$ I1[?]P1 + I2[?]P2 $+\ldots$ + I30[?]P30, where I is the food parameter effect score considering the effect of inflammation obtained from reviewed research articles and $\mathrm{P}$ is the food-specific centered percentile score derived from food data. The DII minimum/maximum levels in pregnant populations in previous JECS study were reported to range from -6.16 to +5.80 .18$

\section{Obstetric outcomes and confounding factors}

PTB was classified into two categories: delivery before 37 weeks and before 34 weeks (severe PTB). LBW was also categorised into two categories: $<2500 \mathrm{~g}$ and $<1500 \mathrm{~g}$ (severe LBW). In this study, hypertensive disorder of pregnancy (HDP) was defined as a new onset of hypertension ([?]140/90 mmHg) after the 20th gestational week for previously normotensive women. Confounding factors were determined by clinical importance, i.e. those believed to be related to PTB and dietary habits. The following items were used as confounding factors: maternal age, maternal smoking status, maternal education, household income, maternal body mass index (BMI) before pregnancy, myoma uteri, adenomyosis, and assisted reproductive technology (ART) pregnancy. Maternal age was categorised into six groups: [?]19, 20-24, 25-29, 30-34, 35-39, and [?] 40 years. Maternal prepregnancy BMI was calculated by dividing the height $(\mathrm{m})$ by the square of the body weight $(\mathrm{kg})$. We categorised participants into three BMI groups as follows: $<18.5,18.5-25.0$, and [?]25.0 kg/m². T1 data provided information on their smoking status during the first trimester: "never smoked," "quit smoking before pregnancy," "quit smoking during early pregnancy," and "kept smoking during pregnancy." Women who "kept smoking during pregnancy" were considered smokers (smoking category); otherwise, they were considered as non-smokers (non-smoking).Maternal education was categorised into four groups as junior high school ( $<10$ years), high school (10-12 years), professional school or university (13-16 years), and graduate school ([?]17 years). Annual household income was categorised into four levels $(<2,000,000 ; 2,000,000-5,999,999$; 6,000,000-9,999,999; and [?]10,000,000 JPY). Maternal participants were also asked to answer the question: "Have you ever been diagnosed with endometriosis (or other pre-pregnancy gynaecological condition, i.e. adenomyosis, uterine myoma) at a medical institution?" Maternal participants who answered "Yes" were classified as having uterine anomaly (or other pre-pregnancy gynaecological condition). The manner of conception was categorised as natural pregnancy or ART pregnancy, with ART defined as conception after in vitro fertilisation and/or intracytoplasmic sperm injection, or cryopreserved, frozen, or blastocyst embryo transfers.

\section{Statistical analyses}

Participants were categorised according to quintiles (Q1 was the most pro-inflammatory group, whereas Q5 was the most anti-inflammatory group) and further stratified into two groups based on the presence or absence of endometriosis. Maternal characteristics were summarised according to the presence of endometriosis. Ttests were conducted to compare continuous variables, and Chi-square tests or Fisher's exact tests were used to compare categorical variables, as appropriate. The extended Mantel-Haenzel Chi-square test for linear trend was used to analyse the trend in proportion. Adjusted odds ratios (aOR) and 95\% confidence intervals (CI) for each obstetric outcome were calculated using a multiple logistic regression model, accounting for maternal age, maternal smoking status, maternal education, household income, maternal prepregnancy BMI, myoma uteri, adenomyosis, and ART pregnancy. To examine the interaction between endometriosis and infertility therapy, endometriosis women were further grouped into pregnancy with ART or pregnancy without ART. Then, the aOR and 95\% CI for the same obstetric outcome were calculated by multiple logistic 
regression model. We accomplished this by using dummy variables for categorical variables composed of more than three categories. SPSS version 24 (IBM Corp., Armonk, NY) was used for the statistical analyses. A $\mathrm{p}$ value $<0.05$ indicated statistical significance.

\section{RESULTS}

The total number of fetal records from 2011 to 2014 in the JECS was 104,102. Of these, 1,994 and 3,278 records were excluded for multiple gestations and insufficient DII data, respectively. Then, 10,432 participants were excluded for having insufficient data. After applying our inclusion criteria, 88,398 participants were eligible for the present study and were then categorised into two groups based on the presence or absence of endometriosis (self-reported) ( $\mathrm{n}=3,249$, endometriosis group; $\mathrm{n}=85,149$ without endometriosis group). Finally, both groups were divided into five categories according to quintiles of their DII score (Figure 1).

Table 1 summarises the basic characteristics of the participants according to the presence of endometriosis. The mean maternal age and maternal age categories were significantly different between the two groups $(\mathrm{p}<.001$ and $\mathrm{p}<0.001$, respectively). The mean DII was significantly higher in the non-endometriosis group $(\mathrm{p}<0.001)$. In the endometriosis group, the rate of uterine myoma, adenomyosis, and ART pregnancy were significantly higher than those in the non-endometriosis group. The categories of maternal education, household income, and BMI were significantly different between the two groups $(\mathrm{p}<0.001, \mathrm{p}<0.001$, and $\mathrm{p}=0.031$, respectively).

Table 2 summarises the trend of obstetric outcomes for both groups according to the DII category. The prevalence of PTB $<37$ and $<34$ weeks, LBW $<2500$ g, and HDP were $4.5 \%, 0.9 \%, 7.9 \%, 0.5 \%$, and $2.8 \%$, respectively, for the non-endometriosis group, and $6.2 \%, 1.2 \%, 10.0 \%, 0.7 \%$, and $3.2 \%$, respectively, for the endometriosis group. Among women with endometriosis, the incidence of LBW $<2500 \mathrm{~g}$ decreased in the DII group ( $\mathrm{p}=0.008)$. Among women with endometriosis, the incidence of PTB $<34$ weeks and LBW $<1500$ $\mathrm{g}$ significantly decreased in the DII group $(\mathrm{p}=0.040$ and $\mathrm{p}=0.003)$.

Table 3 summarises the aORs of obstetric complication according to DII category for both the endometriosis and non-endometriosis group, with Q1 (most pro-inflammatory category) as the reference. The multiple regression analysis shows decreased risk for PTB $<34$ weeks in Q3 (aOR 0.77, 95\% CI 0.62-0.97), Q4 (aOR 0.77, 95\% CI 0.61-0.96), and Q5 (aOR 0.80, 95\% CI 0.64-0.998) for the endometriosis group. For the endometriosis group, Q5 groups had significantly decreased risk of PTB $<34$ weeks (aOR $0.35,95 \%$ CI $0.12-0.99$ ) and $\mathrm{LBW}<1500 \mathrm{~g}$ (aOR $0.13,95 \%$ CI 0.03-0.61). For women with endometriosis without ART, Q5 still significantly decreased the risk of PTB $<34$ weeks (aOR $0.25,95 \%$ CI $0.07-0.83$ ) and LBW $<1500$ g (aOR 0.07, 95\% CI 0.01-0.60).

\section{DISCUSSION}

\section{Main Findings}

Dietary factors have been implicated in the development and severity of endometriosis. ${ }^{21}$ To date, most studies related to diet and endometriosis have focused on incident diagnosis of endometriosis among women based on dietary intake in adulthood. To our knowledge, this is the first report that used the Japanese largest birth cohort and examined the effect of prepregnancy anti-inflammatory diet on obstetric outcome in women with endometriosis. The obstetric outcome was not affected by ART. The magnitude of aORs in the present study suggested a distinctive effect of anti-inflammatory diet on more severe obstetric outcome, specifically PTB before 34 weeks and LBW $<1500 \mathrm{~g}$ among women with endometriosis.

\section{Strength and limitation}

To our knowledge, this is the first large-scale study conducted in Japan with meticulous attention to data collection. Therefore, the results of this study are considered representative of the general pregnant population in Japan. ${ }^{22,23}$ Randomised controlled intervention trials are more likely the best study design; however, it is impossible to conduct long-term controlled trial examining intake of overall diet as exposure. 
Although the present results were not obtained from a randomised controlled study, a prospective birth cohort study can prove the correlation between outcome and exposure assessed before the onset of outcome. Nevertheless, this study also has potential limitations. First, we do not have information on the diagnostic methods of gynaecological complication such as endometriosis, uterine myoma, and adenomyosis. Moreover, of the 3,249 women, the number of women who had active endometriosis during their pregnancies and whether these complications were treated before pregnancy were unclear, because information was based on self-reported questionnaire. Information on these complications in patient's medical records was insufficient, and we did not utilise past medical records of the participating women. In Japan, gynaecologists usually use transvaginal ultrasonography to examine the conditions of the uterus and ovaries at their first visit. A previous study reported that the diagnostic accuracy of endometriosis by vaginal ultrasonography is almost $90 \%$ regardless of its phenotype. ${ }^{24}$ With regard to obstetric outcomes, data were collected prospectively from the medical records by trained research coordinators and medical doctor at the subject institution for all puerperal patients. Therefore, we expect that the maternal gynaecologic condition before pregnancy and outcome of delivery to be accurate. Second, although we accounted for some confounding factors in large portions of the questionnaire, unknown factors that might have affected the occurrence of PTB, LBW, or HDP might have existed.

Third, the DII score of each study participant was calculated using only the FFQ as the basis of the Japanese lifestyle, and JECS participants were Japanese women. Therefore, the DII of this study is not validated yet, and our results may not be applicable to other ethnicities. Fourth, because the FFQ used for calculating the DII score in this study was based on the self-reported information of women during their first trimester, recall bias may be possible, as participants might have had morning sickness and were asked to recall their diet content before pregnancy.

\section{Clinical implication}

Several evidences suggest that endometriosis is associated with the risk of several chronic diseases such as asthma, allergies, and coronary heart disease (CHD). Although the aetiology of endometriosis remains poorly understood, the levels of inflammation-related factors, such as interleukin (IL)-1 and IL-6 and tumour necrosis factor (TNF)-alpha, have been reported to increase in the peritoneal fluid and peripheral blood of women with endometriosis. ${ }^{25,26}$ These reports suggest that endometriosis is associated with local and systemic inflammations. Because chronic inflammation plays key roles in the pathogenesis of allergy-related conditions and CHD, endometriosis may increase the risk of these conditions. Although endometriosis is related to fertility and chronic diseases, clinical importance also focuses on association with adverse obstetric outcomes. In a systematic review and meta-analysis, Zullo et al. reported that women with endometriosis have higher risk of several adverse obstetric complications such as PTB. ${ }^{6}$ Using preliminary JECS dataset, Harada et al. already reported that endometriosis significantly increased the incidence of PTB-related condition such as preterm premature rupture of the membrane. ${ }^{27}$ Pro-inflammatory cytokines, such as IL and TNF, produce prostaglandin (PG) and matrix-degrading enzymes. PG stimulates uterine contractions, whereas degradation of the extracellular matrix leads to preterm rupture of fetal membranes, resulting in PTB. Therefore, antiinflammatory diet against endometriosis, which is a pro-inflammatory condition, is thought to be plausible for PTB prevention.

Recently, interest in preconception health has been increasing, ${ }^{28}$ as preconception is a crucial period for influencing not only pregnancy outcomes but also the long-term health of the mother and her child. Because endometriosis is a chronic health condition, clinical management of women with endometriosis is essential not only for short-term outcomes including successful implantation and pregnancy, but also for promotion of longterm health. The preconception period could be regarded as a 'window of opportunity' to promote maternal health because it represents a time when women are most willing to abandon unhealthy habits. ${ }^{29}$ Until now, preconception care for women with endometriosis was not adequately discussed, considering the need to improve obstetric outcomes and future health. Additionally, preconception diet counselling could assist in providing the motivation to alter food-intake behaviour during pregnancy, ${ }^{30}$ preconception counselling to alter usual diet habit for an anti-inflammatory diet could become a potential management for women with 
endometriosis to reduce the risk of obstetric complication and promote long-term health.

\section{CONCLUSION}

It is reasonable to recommend anti-inflammatory diet to women with endometriosis, as endometriosis is a chronic inflammation. Our study suggests that preconception care, by improving the dietary lifestyle, may improve the perinatal mortality and morbidity of women with endometriosis. Therefore, specialists in endocrinology and infertility should provide medical care not only to achieve short-term outcomes such as a positive pregnancy test, but also to advise on the dietary pattern required to reduce occurrence of obstetric complications in these population. Further studies are required to determine whether preconception care by dietary lifestyle could improve maternal chronic diseases.

\section{Contribution of authorship}

All authors approved the final manuscript. H.K. initiated the concept and H. N. designed the study. T.M. and T.F. provided additional advice. A.S., Y.O., and M.K. collected the data. H.K. analysed the data and wrote the manuscript. A.K., S.Y, M.H., K.F., S.Y., K.H., and the Japan Environment and Children's Study group reviewed the manuscript and gave critical advice.

\section{Disclosure of interests}

None.

\section{Data sharing statement}

Data from JECS are not available for public use.

\section{Acknowledgements}

The findings and conclusions of this article are solely the responsibility of the authors and do not represent the official views of the Ministry of the Environment. The authors are grateful to all participants in the study.

Members of the JECS Group as of 2019: Michihiro Kamijima (principal investigator, Nagoya City University, Nagoya, Japan), Shin Yamazaki (National Institute for Environmental Studies, Tsukuba, Japan), Yukihiro Ohya (National Center for Child Health and Development, Tokyo, Japan), Reiko Kishi (Hokkaido University, Sapporo, Japan), Nobuo Yaegashi (Tohoku University, Sendai, Japan), Koichi Hashimoto (Fukushima Medical University, Fukushima, Japan), Chisato Mori (Chiba University, Chiba, Japan), Shuichi Ito (Yokohama City University, Yokohama, Japan), Zentaro Yamagata (University of Yamanashi, Chuo, Japan), Hidekuni Inadera (University of Toyama, Toyama, Japan), Takeo Nakayama (Kyoto University, Kyoto, Japan), Hiroyasu Iso (Osaka University, Suita, Japan), Masayuki Shima (Hyogo College of Medicine, Nishinomiya, Japan), Youichi Kurozawa (Tottori University, Yonago, Japan), Narufumi Suganuma (Kochi University, Nankoku, Japan), Koichi Kusuhara (University of Occupational and Environmental Health, Kitakyushu, Japan), and Takahiko Katoh (Kumamoto University, Kumamoto, Japan).

Details of Ethics Approval: The Japan Environment and Children's Study protocol was reviewed and approved by the Ministry of the Environment's Institutional Review Board on Epidemiological Studies and by the Ethics Committees of Fukushima Medical University (Approved date: May/2014. No1165).

\section{Funding: None}

\section{REFERENCES}

1. Viganò P, Parazzini F, Somigliana E, Vercellini P. Endometriosis: epidemiology and aetiological factors. Best Pract Res Clin Obstet Gynaecol. 2004 Apr ;18(2) :177-200.

2. Khine YM, Taniguchi F, Harada T. Clinical management of endometriosis-associated infertility. Reprod Med Biol. 2016 Feb 17;15(4) :217-25. 
3. McKinnon BD, Kocbek V, Nirgianakis K, Bersinger NA, Mueller MD. Kinase signaling pathways in endometriosis: potential targets for non-hormonal therapeutics. Hum Reprod Update. 2016 Apr ;22(3):382-403. Epub 2016 Jan 5.

4. Santulli P, Marcellin L, Tosti C, Chouzenoux S, Cerles O, Borghese B, Batteux F, Chapron C. MAP kinases and the inflammatory signaling cascade as targets for the treatment of endometriosis? Expert Opin Ther Targets. 2015 ;19(11):1465-83. Epub 2015 Sep 21.

5. de Ziegler D, Borghese B, Chapron C. Endometriosis and infertility: pathophysiology and management. Lancet. 2010 Aug 28;376(9742):730-8.

6. Zullo F, Spagnolo E, Saccone G, Acunzo M, Xodo S, Ceccaroni M, Berghella V. Endometriosis and obstetrics complications: a systematic review and meta-analysis. Fertil Steril. 2017 Oct ;108(4):66772.e5. Epub 2017 Sep 2.

7. Wu YW, Colford JM Jr. Chorioamnionitis as a risk factor for cerebral palsy: a meta-analysis. JAMA. 2000 Sep 20;284(11): 1417-24.

8. Clark EA, Mele L, Wapner RJ, Spong CY, Sorokin Y, Peaceman A, Iams JD, Leveno KJ, Harper M, Caritis SN, Miodovnik M, Mercer BM, Thorp JM, Ramin SM, Carpenter M, Rouse DJ; Eunice Kennedy Shriver National Institute of Child Health and Human Development Maternal-Fetal Medicine Units Network. Association of fetal inflammation and coagulation pathway gene polymorphisms with neurodevelopmental delay at age 2 years. Am J Obstet Gynecol. 2010 Jul ;203(1):83.e1-83.e10. Epub 2010 Apr 24.

9. Moster D, Lie RT, Markestad T. Long-term medical and social consequences of preterm birth. N Engl J Med. 2008 Jul 17;359(3):262-73.

10. Lopez-Garcia E, Schulze MB, Fung TT, Meigs JB, Rifai N, Manson JE, Hu FB. Major dietary patterns are related to plasma concentrations of markers of inflammation and endothelial dysfunction. Am J Clin Nutr. 2004 Oct ;80(4) :1029-35.

11. Giugliano D, Ceriello A, Esposito K. The effects of diet on inflammation: emphasis on the metabolic syndrome. J Am Coll Cardiol. 2006 Aug 15;48(4):677-85. Epub 2006 Jul 24.

12. Pearson TA, Mensah GA, Alexander RW, Anderson JL, Cannon RO 3rd, Criqui M, Criqui M, Fadl YY, Fortmann SP, Hong Y, Myers GL, Rifai N, Smith SC Jr, Taubert K, Tracy RP, Vinicor F; Centers for Disease Control and Prevention; American Heart Association. Markers of inflammation and cardiovascular disease: application to clinical and public health practice: a statement for healthcare professionals from the Centers for Disease Control and Prevention and the American Heart Association. Circulation. 2003 Jan 28;107(3) :499-511.

13. Ramallal R, Toledo E, Martínez-González MA, Hernández-Hernández A, García-Arellano A, Shivappa N, Hébert JR, Ruiz-Canela M. Dietary inflammatory index and incidence of cardiovascular disease in the SUN cohort. PLoS One. 2015 Sep 4;10(9) :e0135221.

14. Guo H, Niu K, Monma H, Kobayashi Y, Guan L, Sato M, Minamishima D, Nagatomi R. Association of Japanese dietary pattern with serum adiponectin concentration in Japanese adult men. Nutr Metab Cardiovasc Dis. 2012 Mar;22(3):277-84. Epub 2010 Sep 28.

15. Tada N. [Dietary therapy for prevention and treatment of atherosclerosis from the perspective of antiinflammation]. Nihon Rinsho. 2011 Jan ;69(1) :110-8. Japanese.

16. Shivappa N, Steck SE, Hurley TG, Hussey JR, Hébert JR. Designing and developing a literaturederived, population-based dietary inflammatory index. Public Health Nutr. 2014 Aug ;17(8):1689-96. Epub 2013 Aug 14.

17. Phillips CM, Chen LW, Heude B, Bernard JY, Harvey NC, Duijts L, Mensink-Bout SM, Polanska K, Mancano G, Suderman M, Shivappa N, Hébert JR. Dietary inflammatory index and non-communicable disease risk: A narrative review. Nutrients. 2019 Aug 12;11(8) pii:E1873.

18. Ishibashi M, Kyozuka H, Yamaguchi A, Fujimori K, Hosoya M, Yasumura S, Masahito K, Sato A, Ogata Y, Hashimoto K; the Japan Environment and Children's Study (JECS) Group. Effect of proinflammatory diet before pregnancy on gestational age and birth weight: The Japan Environment and Children's Study. Matern Child Nutr. 2019 Apr ;16(2):e12899. Epub 2019 Nov 20.

19. Kawamoto T, Nitta H, Murata K, Toda E, Tsukamoto N, Hasegawa M, Hasegawa M, Yamagata 
Z, Kayama F, Kishi R, Ohya Y, Saito H, Sago H, Okuyama M, Ogata T, Yokoya S, Koresawa Y, Shibata Y, Nakayama S, Michikawa T, Takeuchi A, Satoh H; Working Group of the Epidemiological Research for Children's Environmental Health. Rationale and study design of the Japan Environment and Children's Study (JECS). BMC Public Health. 2014 Jan 10;14 :25.

20. Yokoyama Y, Takachi R, Ishihara J, Ishii Y, Sasazuki S, Sawada N, Shinozawa Y, Tanaka J, Kato E, Kitamura K, Nakamura K, Tsugane S. Validity of short and long self-administered food frequency questionnaires in ranking dietary intake in middle-aged and elderly Japanese in the Japan Public Health Center-Based Prospective Study for the Next Generation (JPHC-NEXT) protocol area. J Epidemiol. 2016 Aug 5;26(8):420-32. Epub 2016 Apr 9.

21. Shafrir AL, Farland LV, Shah DK, Harris HR, Kvaskoff M, Zondervan K, Missmer SA. Risk for and consequences of endometriosis: a critical epidemiologic review. Best Pract Res Clin Obstet Gynaecol. 2018 Aug ;51:1-15. Epub 2018 Jul 3.

22. Yamguchi A, Kyozuka H, Fujimori K, Hosoya M, Yasumura S, Yokoyama T, Sato A, Hashimoto K; Japan Environment and Children's Study Group. Risk of preterm birth, low birthweight and smallfor-gestational-age infants in pregnancies with adenomyosis: a cohort study of the Japan Environment and Children's Study. Acta Obstet Gynecol Scand. 2019 Mar ;98(3):359-64. Epub 2018 Dec 2.

23. Michikawa T, Nitta H, Nakayama SF, Yamazaki S, Isobe T, Tamura K, Suda E, Ono M, Yonemoto J, Iwai-Shimada M, Kobayashi Y, Suzuki G, Kawamoto T; Japan Environment and Children's Study. Baseline profile of participants in the Japan Environment and Children's Study (JECS). J Epidemiol. 2018 Feb 5;28(2):99-104. Epub 2017 Oct 25.

24. Guerriero S, Ajossa S, Minguez JA, Jurado M, Mais V, Melis GB, Alcazar JL. Accuracy of transvaginal ultrasound for diagnosis of deep endometriosis in uterosacral ligaments, rectovaginal septum, vagina and bladder: systematic review and meta-analysis. Ultrasound Obstet Gynecol. 2015 Nov;46(5) :534-45.

25. Pizzo A, Salmeri FM, Ardita FV, Sofo V, Tripepi M, Marsico S. Behaviour of cytokine levels in serum and peritoneal fluid of women with endometriosis. Gynecol Obstet Invest. $2002 ; 54(2)$ : 82-7.

26. Koumantakis E, Matalliotakis I, Neonaki M, Froudarakis G, Georgoulias V. Soluble serum interleukin-2 receptor, interleukin- 6 and interleukin-1a in patients with endometriosis and in controls. Arch Gynecol Obstet. $1994 ; 255(3): 107-12$.

27. Harada T, Taniguchi F, Onishi K, Kurozawa Y, Hayashi K, Harada T; Japan Environment \& Children's Study Group. Obstetrical complications in women with endometriosis: a cohort study in Japan. PLoS One. 2016 Dec 22;11(12) :e0168476.

28. Stephenson J, Vogel C, Hall J, Hutchinson J, Mann S, Duncan H, Woods-Townsend K, de Lusignan S, Poston L, Cade J, Godfrey K, Hanson M, Barrett G, Barker M, Conti G, Shannon G, Colbourn T; Preconception Partnership. Preconception health in England: a proposal for annual reporting with core metrics. Lancet. 2019 Jun 1;393(10187):2262-71.

29. Simon C. Introduction: preconceptional care: do we have to care? Fertil Steril. 2019 Oct ;112(4) :611-2.

30. Grieger JA, Grzeskowiak LE, Clifton VL. Preconception dietary patterns in human pregnancies are associated with preterm delivery. J Nutr. 2014 Jul;144(7):1075-80. Epub 2014 Apr 30.

\section{Figure Caption}

Figure 1 Study flow

TABLE 1. BASIC CHARACTERISTICS OF THE PARTICIPANTS ACCORDING TO THE PRESENCE OR ABSENCE OF ENDOMETRIOSIS .

\begin{tabular}{llll}
\hline Variable & Endometriosis (+) & Endometriosis (-) & p value \\
\hline & $\mathrm{N}=3249$ & $\mathrm{~N}=85149$ & \\
Maternal age, mean years (SD) & $32.9(4 \cdot 5)$ & $31 \cdot 3(4 \cdot 9)$ & $<0 \cdot 001^{\mathrm{a}}$ \\
Maternal age category, \% & & & $? \dot{\iota} ?$ \\
19 & $0 \cdot 1$ & $0 \cdot 6$ & $<0 \cdot 001^{\mathrm{b}}$ \\
$20-24$ & $3 \cdot 2$ & 8.5 &
\end{tabular}




\begin{tabular}{|c|c|c|c|}
\hline Variable & Endometriosis $(+)$ & Endometriosis (-) & $\mathrm{p}$ value \\
\hline $25-29$ & $20 \cdot 3$ & 28 & \\
\hline $30-34$ & $37 \cdot 7$ & $35 \cdot 9$ & \\
\hline $35-39$ & $31 \cdot 7$ & $22 \cdot 5$ & $? \gtreqless ?$ \\
\hline 40 & $7 \cdot 1$ & 4.5 & \\
\hline DII before pregnancy, mean (SD) & $-0 \cdot 38(2 \cdot 51)$ & $-0 \cdot 02(2 \cdot 62)$ & $<0 \cdot 001^{\mathrm{a}}$ \\
\hline \multicolumn{4}{|l|}{ DII category, $\%$} \\
\hline Q1 (most proinflammatory group) & $14 \cdot 3$ & $19 \cdot 8$ & $0 \cdot 001^{\mathrm{b}}$ \\
\hline Q2 & $19 \cdot 1$ & $20 \cdot 2$ & \\
\hline Q3 & $21 \cdot 6$ & $20 \cdot 1$ & \\
\hline Q4 & 22 & $20 \cdot 1$ & \\
\hline Q5 (most anti-inflammatory group) & 23 & $20 \cdot 1$ & \\
\hline Maternal smoking, $\%$ & $4 \cdot 9$ & $4 \cdot 6$ & $0.528^{\mathrm{b}}$ \\
\hline \multicolumn{4}{|l|}{ Maternal education, \% } \\
\hline$<10$ years & $3 \cdot 6$ & $4 \cdot 5$ & $<0 \cdot 001^{\mathrm{b}}$ \\
\hline 10-12 years & 27 & $30 \cdot 8$ & \\
\hline $13-16$ years & $45 \cdot 5$ & $42 \cdot 2$ & $? \gtreqless ?$ \\
\hline 17 years & $23 \cdot 9$ & $22 \cdot 4$ & \\
\hline \multicolumn{4}{|l|}{ Household income } \\
\hline$<2,000,000$ JPY & $4 \cdot 4$ & $5 \cdot 7$ & $<0 \cdot 001^{\mathrm{b}}$ \\
\hline 2,000,000-5,999,999 JPY & $64 \cdot 1$ & $67 \cdot 8$ & \\
\hline 6,000,000-9,999,999 JPY & $26 \cdot 3$ & $22 \cdot 3$ & $? \gtreqless ?$ \\
\hline 10,000,000 JPY & $5 \cdot 2$ & $4 \cdot 2$ & \\
\hline \multicolumn{4}{|l|}{ BMI, $\%$} \\
\hline$<18.5$ & $15 \cdot 6$ & 16 & $0 \cdot 031^{\mathrm{b}}$ \\
\hline $18.5-24.9$ & $75 \cdot 1$ & $73 \cdot 3$ & $? i ?$ \\
\hline 25 & $9 \cdot 3$ & $10 \cdot 7$ & \\
\hline Uterine myoma, \% & $16 \cdot 1$ & $5 \cdot 8$ & $<0 \cdot 001^{\mathrm{b}}$ \\
\hline Adenomyosis, $\%$ & $3 \cdot 8$ & $0 \cdot 2$ & $<0 \cdot 001^{\mathrm{b}}$ \\
\hline ART pregnancy, $\%$ & $10 \cdot 7$ & $2 \cdot 7$ & $<0.001^{b}$ \\
\hline
\end{tabular}

SD, standard deviation; ART, assisted reproductive technology; BMI, body mass index; DII, dietary inflammatory index; JPY, Japanese Yen

${ }^{a}$ p-value, t-test

${ }^{\mathrm{b}} \mathrm{p}$-value, chi-square test

TABLE 2. TRENDS OF OBSTETRIC OUTCOMES FOR BOTH GROUPS ACCORDING TO DII CATEGORY

\begin{tabular}{llllll}
\hline Outcome & Total , \% $(\mathrm{n})$ & Quintile for DII & Quintile for DII & Quintile for DII & Quintile \\
\hline & & Q1 (most pro-inflammatory group) & Q2 & Q3 & Q4 \\
PTB $<37$ wks, & & & 4.5 & 4.5 & 4.3 \\
Endometriosis (-) & $4.5(3844 / 84900)$ & 4.5 & 6.5 & 6.1 & 6.6 \\
Endometriosis (+) & $6.2(202 / 3236)$ & 6.7 & & & 0.9 \\
PTB $<34$ wks, & & & 0.9 & 0.8 & 1.1 \\
Endometriosis (-) & $0.9(786 / 84900)$ & 1.1 & 1.1 & 0.9 & 7.4 \\
Endometriosis (+) & $1.2(38 / 3236)$ & 2.4 & 8.3 & 7.5 & \\
LBW $<2500$ g, & & & & & \\
Endometriosis (-) & $7.9(6720 / 84873)$ & 8.4 & &
\end{tabular}




\begin{tabular}{llllll}
\hline Outcome & Total , \% $(\mathrm{n})$ & Quintile for DII & Quintile for DII & Quintile for DII & Quintile \\
\hline Endometriosis (+) & $10.0(323 / 3238)$ & 11.4 & 10.7 & 9.6 & 10.9 \\
LBW < 1500 g, & & & & & 0.5 \\
Endometriosis (-) & $0.5(453 / 84873)$ & 0.6 & 0.6 & 0.5 & 0.5 \\
Endometriosis (+) & $0.7(24 / 3238)$ & 2.2 & & & \\
HDP & & & 2.8 & 2.7 & 2.6 \\
Endometriosis (-) & $2.8(2363 / 85149)$ & 3.0 & 2.3 & 2.4 & 3.9 \\
Endometriosis (+) & $3.2(105 / 3249)$ & 4.5 &
\end{tabular}

DII, dietary inflammatory index; HDP, hypertensive disorder of pregnancy; LBW, low birth weight; PTB, preterm birth

${ }^{a}$ p-value, extended Mantel-Haenzel Chi-square test

\section{TABLE 3 RELATION BETWEEN DII AND OBSTETRIC OUTCOMES FOR EN- DOMETRIOSIS GROUPS}

\begin{tabular}{|c|c|c|c|c|c|c|c|c|}
\hline & & & & $\begin{array}{l}\text { Quintile for } \\
\text { DII }\end{array}$ & $\begin{array}{l}\text { Quintile for } \\
\text { DII }\end{array}$ & $\begin{array}{l}\text { Quintile for } \\
\text { DII }\end{array}$ & $\begin{array}{l}\text { Quintile for } \\
\text { DII }\end{array}$ & $\begin{array}{l}\text { Quintil } \\
\text { DII }\end{array}$ \\
\hline & Endometriosis & $\begin{array}{l}\text { s Total, \% } \\
\text { (n) }\end{array}$ & $\begin{array}{l}\text { Q1 } \\
\text { Most } \\
\text { pro- } \\
\text { inflammatory }\end{array}$ & $\begin{array}{l}\text { Q1 } \\
\text { Most } \\
\text { pro- } \\
\text { inflammatory }\end{array}$ & Q2 & Q3 & Q4 & $\begin{array}{l}\text { Q5 } \\
\text { Most } \\
\text { anti } \\
\text { inflamı }\end{array}$ \\
\hline $\begin{array}{l}\text { PTB } \\
<37 \\
\text { weeks }\end{array}$ & & & & & & & & \\
\hline $\begin{array}{l}\mathrm{aOR}^{1} \\
(95 \% \\
\mathrm{CI})\end{array}$ & $(-)$ & $\begin{array}{l}4.5 \\
(3844 / 84900)\end{array}$ & 1 (Ref) & 1 (Ref) & $\begin{array}{l}0.99 \\
(0.89- \\
1.10)\end{array}$ & $\begin{array}{l}0.99 \\
(0.89- \\
1.09)\end{array}$ & $\begin{array}{l}0.93 \\
(0.83- \\
1.03)\end{array}$ & $\begin{array}{l}1.03 \\
(0.92- \\
1.14)\end{array}$ \\
\hline $\begin{array}{l}\mathrm{aOR}^{1} \\
(95 \% \\
\mathrm{CI})\end{array}$ & $(+)$ & $\begin{array}{l}6.2 \\
(202 / 3236)\end{array}$ & 1 (Ref) & 1 (Ref) & $\begin{array}{l}0.92 \\
(0.56- \\
1.52)\end{array}$ & $\begin{array}{l}0.84 \\
(0.51- \\
1.37)\end{array}$ & $\begin{array}{l}0.97 \\
(0.60- \\
1.57)\end{array}$ & $\begin{array}{l}0.80 \\
(0.49- \\
1.31)\end{array}$ \\
\hline $\begin{array}{l}\mathrm{aOR}^{2} \\
(95 \% \\
\mathrm{CI})\end{array}$ & $\begin{array}{l}(+) \\
\text { with } \\
\text { ART }\end{array}$ & $\begin{array}{l}7.8 \\
(27 / 345)\end{array}$ & 1 (Ref) & 1 (Ref) & $\begin{array}{l}0.29 \\
(0.06- \\
1.38)\end{array}$ & $\begin{array}{l}0.26 \\
(0.06- \\
1.04)\end{array}$ & $\begin{array}{l}0.42 \\
(0.12- \\
1.49)\end{array}$ & $\begin{array}{l}0.82 \\
(0.24- \\
2.78)\end{array}$ \\
\hline $\begin{array}{l}\mathrm{aOR}^{2} \\
(95 \% \\
\mathrm{CI})\end{array}$ & $\begin{array}{l}(+) \\
\text { without } \\
\text { ART }\end{array}$ & $\begin{array}{l}6.1 \\
(175 / 2891)\end{array}$ & 1 (Ref) & 1 (Ref) & $\begin{array}{l}1.05 \\
(0.61- \\
1.79)\end{array}$ & $\begin{array}{l}0.98 \\
(0.57- \\
1.67)\end{array}$ & $\begin{array}{l}1.07 \\
(0.63- \\
1.82)\end{array}$ & $\begin{array}{l}0.80 \\
(0.47- \\
1.39)\end{array}$ \\
\hline $\begin{array}{l}\text { PTB } \\
<34 \\
\text { weeks }\end{array}$ & & & & & & & & \\
\hline $\begin{array}{l}\mathrm{aOR}{ }^{1} \\
(95 \% \\
\mathrm{CI})\end{array}$ & $(-)$ & $\begin{array}{l}0.9 \\
(786 / 84900)\end{array}$ & 1 (Ref) & 1 (Ref) & $\begin{array}{l}0.86 \\
(0.69- \\
1.07)\end{array}$ & $\begin{array}{l}0.77 \\
(0.62- \\
0.97)\end{array}$ & $\begin{array}{l}0.77 \\
(0.61- \\
0.96)\end{array}$ & $\begin{array}{l}0.80 \\
(0.64- \\
0.998)\end{array}$ \\
\hline $\begin{array}{l}\mathrm{aOR}^{1} \\
(95 \% \\
\mathrm{CI})\end{array}$ & $(+)$ & $\begin{array}{l}1.2 \\
(38 / 3236)\end{array}$ & 1 (Ref) & 1 (Ref) & $\begin{array}{l}0.53 \\
(0.20- \\
1.42)\end{array}$ & $\begin{array}{l}0.37 \\
(0.13- \\
1.04)\end{array}$ & $\begin{array}{l}0.50 \\
(0.19- \\
1.30)\end{array}$ & $\begin{array}{l}0.35 \\
(0.12- \\
0.99)\end{array}$ \\
\hline $\begin{array}{l}\mathrm{aOR}^{2} \\
(95 \% \\
\mathrm{CI})\end{array}$ & $\begin{array}{l}(+) \\
\text { with } \\
\text { ART }\end{array}$ & $\begin{array}{l}1.4 \\
(5 / 345)\end{array}$ & 1 (Ref) & 1 (Ref) & $\mathrm{NA}$ & $\begin{array}{l}0.40 \\
(0.02- \\
7.14)\end{array}$ & $\begin{array}{l}0.39 \\
(0.02- \\
7.39)\end{array}$ & $\begin{array}{l}1.35 \\
(0.11- \\
17.1)\end{array}$ \\
\hline
\end{tabular}




\begin{tabular}{|c|c|c|c|c|c|c|c|c|}
\hline & & & & $\begin{array}{l}\text { Quintile for } \\
\text { DII }\end{array}$ & $\begin{array}{l}\text { Quintile for } \\
\text { DII }\end{array}$ & $\begin{array}{l}\text { Quintile for } \\
\text { DII }\end{array}$ & $\begin{array}{l}\text { Quintile for } \\
\text { DII }\end{array}$ & $\begin{array}{l}\text { Quintil } \\
\text { DII }\end{array}$ \\
\hline $\begin{array}{l}\mathrm{aOR}^{2} \\
(95 \% \\
\mathrm{CI})\end{array}$ & $\begin{array}{l}(+) \\
\text { without } \\
\text { ART }\end{array}$ & $\begin{array}{l}1.1 \\
(33 / 2891)\end{array}$ & 1 (Ref) & 1 (Ref) & $\begin{array}{l}0.58 \\
(0.21- \\
1.59)\end{array}$ & $\begin{array}{l}0.35 \\
(0.12- \\
1.08)\end{array}$ & $\begin{array}{l}0.51 \\
(0.18- \\
1.41)\end{array}$ & $\begin{array}{l}0.25 \\
(0.07- \\
0.83)\end{array}$ \\
\hline $\begin{array}{l}\text { LBW } \\
<2500 \text { g }\end{array}$ & & & & & & & & \\
\hline $\begin{array}{l}\mathrm{aOR}^{1} \\
(95 \% \\
\mathrm{CI})\end{array}$ & $(-)$ & $\begin{array}{l}7.9 \\
(6720 / 84873)\end{array}$ & 1 (Ref) & 1 (Ref) & $\begin{array}{l}0.98 \\
(0.91- \\
1.06)\end{array}$ & $\begin{array}{l}0.88 \\
(0.81- \\
0.95)\end{array}$ & $\begin{array}{l}0.88 \\
(0.81- \\
0.95)\end{array}$ & $\begin{array}{l}0.94 \\
(0.86- \\
1.01)\end{array}$ \\
\hline $\begin{array}{l}\mathrm{aOR}^{1} \\
(95 \% \\
\mathrm{CI})\end{array}$ & $(+)$ & $\begin{array}{l}10.0 \\
(323 / 3238)\end{array}$ & 1 (Ref) & 1 (Ref) & $\begin{array}{l}0.95 \\
(0.64- \\
1.41)\end{array}$ & $\begin{array}{l}0.82 \\
(0.55- \\
1.21)\end{array}$ & $\begin{array}{l}0.96 \\
(0.65- \\
1.40)\end{array}$ & $\begin{array}{l}0.69 \\
(0.46- \\
1.04)\end{array}$ \\
\hline $\begin{array}{l}\mathrm{aOR}^{2} \\
(95 \% \\
\mathrm{CI})\end{array}$ & $\begin{array}{l}(+) \\
\text { with } \\
\text { ART }\end{array}$ & $\begin{array}{l}10.1 \\
(35 / 345)\end{array}$ & 1 (Ref) & 1 (Ref) & $\begin{array}{l}0.82 \\
(0.26- \\
2.59)\end{array}$ & $\begin{array}{l}0.20 \\
(0.06- \\
0.71)\end{array}$ & $\begin{array}{l}0.38 \\
(0.13- \\
1.17)\end{array}$ & $\begin{array}{l}0.20 \\
(0.05- \\
0.84)\end{array}$ \\
\hline $\begin{array}{l}\mathrm{aOR}^{2} \\
(95 \% \\
\mathrm{CI})\end{array}$ & $\begin{array}{l}(+) \\
\text { without } \\
\text { ART }\end{array}$ & $\begin{array}{l}10.0 \\
(288 / 2893)\end{array}$ & 1 (Ref) & 1 (Ref) & $\begin{array}{l}0.96 \\
(0.63- \\
1.46)\end{array}$ & $\begin{array}{l}0.93 \\
(0.62- \\
1.42)\end{array}$ & $\begin{array}{l}1.02 \\
(0.67- \\
1.54)\end{array}$ & $\begin{array}{l}0.78 \\
(0.51- \\
1.19)\end{array}$ \\
\hline $\begin{array}{l}\text { LBW } \\
<1500 \text { g }\end{array}$ & & & & & & & & \\
\hline $\begin{array}{l}\mathrm{aOR}^{1} \\
(95 \% \\
\mathrm{CI})\end{array}$ & $(-)$ & $\begin{array}{l}0.5 \\
(453 / 84873)\end{array}$ & 1 (Ref) & 1 (Ref) & $\begin{array}{l}0.94 \\
(0.70- \\
1.25)\end{array}$ & $\begin{array}{l}0.83 \\
(0.62- \\
1.12)\end{array}$ & $\begin{array}{l}0.73 \\
(0.54- \\
0.99)\end{array}$ & $\begin{array}{l}0.88 \\
(0.66- \\
1.18)\end{array}$ \\
\hline $\begin{array}{l}\mathrm{aOR}^{1} \\
(95 \% \\
\mathrm{CI})\end{array}$ & $(+)$ & $\begin{array}{l}0.7 \\
(24 / 3238)\end{array}$ & 1 (Ref) & 1 (Ref) & $\begin{array}{l}0.24 \\
(0.06- \\
0.91)\end{array}$ & $\begin{array}{l}0.27 \\
(0.08- \\
0.89)\end{array}$ & $\begin{array}{l}0.35 \\
(0.11- \\
1.07)\end{array}$ & $\begin{array}{l}0.13 \\
(0.03- \\
0.61)\end{array}$ \\
\hline $\begin{array}{l}\mathrm{aOR}^{2} \\
(95 \%\end{array}$ & $\begin{array}{l}(+) \\
\text { with }\end{array}$ & $\begin{array}{l}0.6 \\
(2 / 345)\end{array}$ & 1 (Ref) & 1 (Ref) & $\mathrm{NA}$ & NA & NA & NA \\
\hline CI) & ART & & & & & & & \\
\hline $\begin{array}{l}\mathrm{aOR}^{2} \\
(95 \% \\
\mathrm{CI}) \\
\mathrm{HDP}\end{array}$ & $\begin{array}{l}(+) \\
\text { without } \\
\text { ART }\end{array}$ & $\begin{array}{l}0.8 \\
(22 / 2893)\end{array}$ & 1 (Ref) & 1 (Ref) & $\begin{array}{l}0.27 \\
(0.07- \\
1.05)\end{array}$ & $\begin{array}{l}0.32 \\
(0.09- \\
1.10)\end{array}$ & $\begin{array}{l}0.41 \\
(0.13- \\
1.29)\end{array}$ & $\begin{array}{l}0.07 \\
(0.01- \\
0.60)\end{array}$ \\
\hline $\begin{array}{l}\mathrm{aOR}^{1} \\
(95 \% \\
\mathrm{CI})\end{array}$ & $(-)$ & $\begin{array}{l}2.8 \\
(2363 / 85149)\end{array}$ & 1 (Ref) & 1 (Ref) & $\begin{array}{l}0.90 \\
(0.79- \\
1.03)\end{array}$ & $\begin{array}{l}0.87 \\
(0.77- \\
0.995)\end{array}$ & $\begin{array}{l}0.85 \\
(0.74- \\
0.97)\end{array}$ & $\begin{array}{l}0.84 \\
(0.73- \\
0.95)\end{array}$ \\
\hline $\begin{array}{l}\mathrm{aOR}{ }^{1} \\
(95 \% \\
\mathrm{CI})\end{array}$ & $(+)$ & $\begin{array}{l}3.2 \\
(105 / 3249)\end{array}$ & 1 (Ref) & 1 (Ref) & $\begin{array}{l}0.52 \\
(0.26- \\
1.04)\end{array}$ & $\begin{array}{l}0.52 \\
(0.27- \\
1.00)\end{array}$ & $\begin{array}{l}0.79 \\
(0.44- \\
1.45)\end{array}$ & $\begin{array}{l}0.74 \\
(0.40- \\
1.35)\end{array}$ \\
\hline $\begin{array}{l}\mathrm{aOR}^{2} \\
(95 \% \\
\mathrm{CI})\end{array}$ & $\begin{array}{l}(+) \\
\text { with } \\
\text { ART }\end{array}$ & $\begin{array}{l}5.8 \\
(20 / 347)\end{array}$ & 1 (Ref) & 1 (Ref) & $\begin{array}{l}0.90 \\
(0.22- \\
3.06)\end{array}$ & $\begin{array}{l}0.45 \\
(0.11- \\
1.86)\end{array}$ & $\begin{array}{l}0.68 \\
(0.18- \\
2.54)\end{array}$ & $\begin{array}{l}0.11 \\
(0.01- \\
1.02)\end{array}$ \\
\hline $\begin{array}{l}\mathrm{aOR}^{2} \\
(95 \% \\
\mathrm{CI})\end{array}$ & $\begin{array}{l}(+) \\
\text { without } \\
\text { ART }\end{array}$ & $\begin{array}{l}2.9 \\
(85 / 2902)\end{array}$ & 1 (Ref) & 1 (Ref) & $\begin{array}{l}0.45 \\
(0.20- \\
1.02)\end{array}$ & $\begin{array}{l}0.53 \\
(0.25- \\
1.13)\end{array}$ & $\begin{array}{l}0.84 \\
(0.43- \\
1.66)\end{array}$ & $\begin{array}{l}0.91 \\
(0.47- \\
1.77)\end{array}$ \\
\hline
\end{tabular}

aOR, adjusted odds ratio; CI, confidence interval; DII, dietary inflammatory index; HDP, hypertensive disorder of pregnancy; LBW, low birth weight; PTB, preterm birth; Ref, reference. ART, assisted reproductive technology. NA, not available. 
$\mathrm{aOR}^{1}$ was calculated by logistic regression analysis, including maternal age, maternal smoking status, maternal education, household income, maternal prepregnancy body mass index, myoma uteri, adenomyosis, and assisted reproductive technology.

$\mathrm{aOR}^{2}$ was calculated by logistic regression analysis, including maternal age, maternal smoking status, maternal education, household income, maternal prepregnancy body mass index, myoma uteri, and adenomyosis.

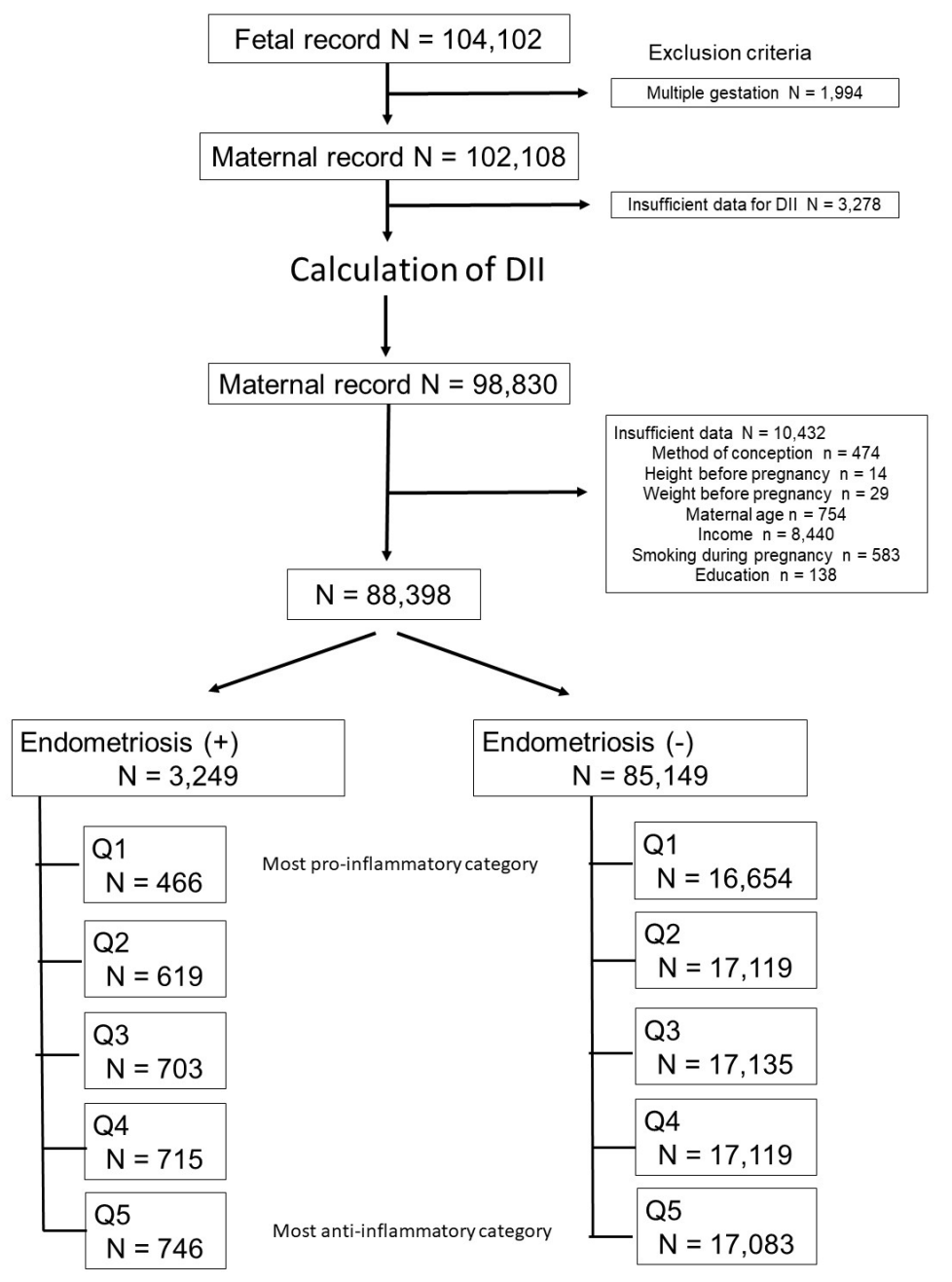

